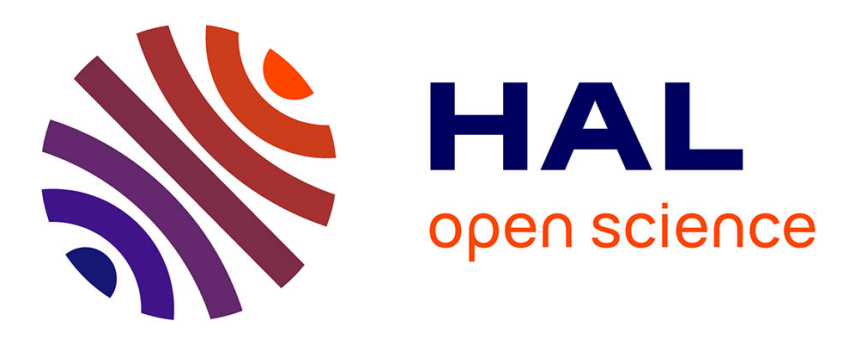

\title{
Analysis of GNSS integrity requirements for road user charging applications
}

\author{
Daniel Salós, Christophe Macabiau, Anaïs Martineau, Bernard Bonhoure, \\ Damien Kubrak
}

\section{- To cite this version:}

Daniel Salós, Christophe Macabiau, Anaïs Martineau, Bernard Bonhoure, Damien Kubrak. Analysis of GNSS integrity requirements for road user charging applications. NAVITEC 2010, 5th ESA Workshop on Satellite Navigation Technologies and European Workshop on GNSS Signals, Dec 2010, Noordwijk, Netherlands. pp 1-8, 10.1109/NAVITEC.2010.5708007 . hal-01022508

\section{HAL Id: hal-01022508 \\ https://hal-enac.archives-ouvertes.fr/hal-01022508}

Submitted on 29 Sep 2014

HAL is a multi-disciplinary open access archive for the deposit and dissemination of scientific research documents, whether they are published or not. The documents may come from teaching and research institutions in France or abroad, or from public or private research centers.
L'archive ouverte pluridisciplinaire HAL, est destinée au dépôt et à la diffusion de documents scientifiques de niveau recherche, publiés ou non, émanant des établissements d'enseignement et de recherche français ou étrangers, des laboratoires publics ou privés. 


\section{Analysis of GNSS Integrity Requirements for Road User Charging Applications}

\author{
Daniel Salós \\ TéSA/ENAC \\ Toulouse, France
}

\author{
Christophe Macabiau, Anaïs Martineau \\ ENAC \\ Toulouse, France
}

\author{
Bernard Bonhoure \\ CNES \\ Toulouse, France
}

\author{
Damien Kubrak \\ Thales Alenia Space \\ Toulouse, France
}

\begin{abstract}
GNSS-based Road User Charging (RUC) systems are particularly interesting because of their flexibility and reduced roadside infrastructure. At present, truck toll collection systems based on GPS receivers installed on the vehicles are already deployed in German and Slovak motorways. Reliability of road tolling systems is fundamental in order to limit the loss of revenue because of undercharging and the user claims because of overcharging. Consequently, GNSS integrity monitoring plays a key role in such systems, providing trustful positioning data that keep position errors and their associated legal or economical consequences within given limits. Nevertheless, the design of GNSS integrity algorithms like RAIM requires a deep knowledge of the characteristics of the application and GNSS errors. This paper analyzes the required parameters to develop RAIM algorithms for road tolling applications in urban and rural environments.
\end{abstract}

Keywords- GNSS integrity; RAIM; Road User Charging; urban environment

\section{INTRODUCTION}

Road User Charging (RUC) systems are mechanisms through which vehicles are charged for travelling through a determinate area or road. Examples of RUC are the tolls in motorways or congestion charged zones. GNSS-based RUC are particularly interesting because they provide free-flow charging (they do not require the vehicle to stop), a high degree of flexibility in the design of the charged areas and their fees, and a reduced number of roadside infrastructures. Because of these reasons, together with the possibility of interoperability of RUC systems deployed in different countries, the European Directive 2004/52/EC recommends the application of satellite positioning and mobile communications technologies in the new electronic toll systems [1].

At the present time, GPS-based RUC systems are already used to charge trucks in the German and Slovak motorway networks and certain expressways [2], [3]. Moreover, GNSS technology is being considered in other RUC projects like the different payment for mobility (ABvM) in the Netherlands [4] or the heavy goods vehicle eco-tax in France [5].

Navigation systems are not exempt from errors. Positions estimated by GNSS under nominal performance conditions are affected by different error sources such as receiver thermal noise or multipath, to which system failures can be eventually added. GNSS-based RUC systems do not tolerate uncontrolled position errors as some of them may lead to incorrect charging decisions, which in turn cause loss of revenues if the amount of money charged to a user is lower than it should (undercharging), or user claims and the consequently loss of credibility on the system if the amount of money charged to the user is higher than it should (overcharging). Thus, GNSS integrity monitoring play a key role in road charging systems controlling the presence of excessively large position errors and alerting when it is not possible to estimate the position with the required integrity specifications.

The design of GNSS integrity monitoring algorithms needs a detailed characterization of the required performance and the expected errors. Moreover, road tolling systems should work in urban and suburban environments, where GNSS integrity monitoring might be a challenging task due to the reduced satellite visibility and error sources like multipath. The aim of this paper is to provide the models and parameters needed in the design of integrity monitoring algorithms, in particular RAIM (Receiver Autonomous Integrity Monitoring), for road tolling applications in urban environments.

The paper is organized as follows. Section II introduces integrity monitoring concepts and the parameters needed in the design of RAIM algorithms. Next sections study the different parameters needed to design RAIM algorithms suitable for road tolling applications. Section III relates the integrity requirements of the application with those of GNSS navigation. Finally, sections IV and V present the error characterization in the nominal and faulty cases.

\section{GNSS INTEGRITY MONITORING FOR ROAD TOLLING}

\section{A. GNSS integrity parameters}

Only horizontal position errors need to be monitored in road tolling. Then, GNSS integrity requirements can be defined by the following parameters [6]:

- The integrity risk $\left(\mathrm{P}_{\text {int }}\right)$, is the required maximum probability that a GNSS receiver equipped with integrity monitoring algorithms provides a position failure without alerting the user.

- The horizontal alert limit (HAL), is the radius of a circle with its center at the true position, that describes the region that is required to contain the estimated horizontal position with the required probability. In other words, it defines the maximum tolerable horizontal position error. A positioning failure is 
defined to occur whenever the difference between the estimated and true position exceeds the HAL.

Other applications include a third parameter: the maximum time to alert (TTE). Nevertheless, road tolling may be performed off-line, and the design of snapshot RAIM does not depend on the TTE, so its value has not been set yet for RUC.

\section{B. Receiver autonomous integrity monitoring (RAIM)}

This paper addresses the design needs of receiver autonomous integrity monitoring (RAIM) techniques, which are algorithms performed at the GNSS receiver itself that only use ranging measurements.

Some properties of RAIM are:

- RAIM is based on redundancy; the detection of a single erroneous range measurement requires at least one satellite more than the minimum to estimate the position.

- RAIM is performed by the receiver without any external information but measured ranging sources, so it is possible to design a RAIM with performance adapted to the application needs (in opposition to other external integrity monitoring systems like SBAS, which performance is fixed and tuned to meet mainly civil aviation requirements).

- $\quad$ Since RAIM directly works with ranges measured by the user, it deals with the whole measurement error, including local errors as multipath that cannot be treated by other systems based on ground stations.

- RAIM can be used with any GNSS (standalone or multi-constellation), once the error characterization of each system is known.

Note that although SBAS integrity performance is fixed, SBAS error corrections and their respective residual error models are suitable for road tolling applications.

RAIM performs two functions at each epoch:

1) Availability check of the fault detection (FD) function calculating the horizontal protection level (HPL)

- HPL<HAL: FD available.

- HPL>HAL: FD not available

2) If it is available, the FD algorithm monitors the presence of horizontal position failures.

The HPL is the radius of a circle with its center at the true position that describes the region where it is assured to contain the estimated horizontal position within the missed alert $\left(\mathrm{P}_{\mathrm{MA}}\right)$ and false alert $\left(\mathrm{P}_{\mathrm{FA}}\right)$ requirements [6]. It is a function of the satellite-user geometry and of the expected pseudorange error, but not of the current measurements.

RAIM may include the capability of fault detection and exclusion (FDE), for what additional redundancy is required, as well as a horizontal exclusion level (HEL) check.

\section{Required parameters in the RAIM design}

The inputs for designing RAIM algorithms are their required performance $\left(\mathrm{P}_{\mathrm{MA}}, \mathrm{P}_{\mathrm{FA}}\right)$, defined with respect to the GNSS integrity requirements $\left(\mathrm{P}_{\text {int }}, \mathrm{HAL}\right)$. RAIM performance can be set thanks to the knowledge of the nominal pseudorange measurement model. Moreover, the threat model indicates the minimum errors the RAIM must be able to detect.

Let's see an example of how these parameters are used in the design of a snapshot least squares residual (LSR) RAIM [7]. First, once the user position has been obtained with a LS estimator, a test statistic is built, in this case based on the squared sum of the pseudorange residuals and the expected measurement error. The RAIM decides that there is a position failure when the test statistic is higher than a threshold $\mathrm{T}$. The test statistic pdf is known in both fault-free and faulty conditions. Then, the threshold can set so that the $\mathrm{P}_{\mathrm{FA}}$ is met in the fault free case. Afterwards, the minimum pseudorange bias the RAIM is able detect with required $\mathrm{P}_{\mathrm{MA}}$ in the most difficult to detect satellite with the threshold $\mathrm{T}$ is determined. It should be checked if the minimum detectable bias is consistent with the threat model.

To sum up, the parameters needed to design a RAIM are:

- integrity requirements $\left(\mathrm{P}_{\text {int }}, \mathrm{HAL}\right)$

- $\quad$ error characterization (nominal and faulty conditions)

- $\quad$ RAIM performance $\left(\mathrm{P}_{\mathrm{MA}}, \mathrm{P}_{\mathrm{FA}}\right)$

\section{APPLICATION AND GNSS INTEGRITY REQUIREMENTS}

Application integrity requirements set the minimum performance of the service provided. In road tolling they may define for instance the maximum percentage the invoice sent to the users is allowed to deviate from the correct one. Nevertheless, RAIM performance is given in terms of $\mathrm{P}_{\mathrm{MA}}$, which in turn depends on the GNSS integrity risk $\mathrm{P}_{\text {int }}$. In order to find the relation between RUC and GNSS integrity requirements, an intermediate level of requirements on geoobject recognition is needed. This section provides the relation between the different levels of requirements and proposes possible values for them.

\section{A. RUC integrity requirements}

Let's define the application integrity requirement as the maximum percentage (x \%) the calculated charge is allowed to deviate from the real one, at a specified minimum percentage (X \%) of calculated invoices. For instance, ref. [5] states that "the requirement set for the registration unit is that the amount, corresponding to the distances recorded over a one-month period, may not deviate by more than 1\% from a 'perfect' measurement in 99\% of cases". The requirement may refer only to over- or under-charging, or to the combined effect of both. The invoice period has been set to one month.

\section{B. Geo-object recognition integrity requirements}

A road tolling method based on geo-fencing is considered: the road network is divided into segments defined by virtual perimeters, which constitute the basic charging units. That is, a user is charged the price of a given road segment if the RUC system decides, from the user's GNSS positioning and integrity 
data, that the user has travelled through it. The segment's fee may depend on its length, vehicle type, the time of the day, the geographical area, etc. Distance-based charging is possible by selecting road segments with only one entrance and one exit. The total amount of the invoice is the sum of the fees of each road segment where the user has been detected during the invoice period.

Invoice requirements can be expressed in terms of road segment detection (also known as geo-object recognition) performance. Assuming that all geo-objects have the same fee and the same probabilities of false recognition $\left(\mathrm{P}_{\mathrm{FR}}\right)$ and missed recognition $\left(\mathrm{P}_{\mathrm{MR}}\right)$, the probability of $\mathrm{n}$ erroneously recognized (under- or over-charged) geo-objects in an invoice with $\mathrm{N}$ geoobjects involved is:

$$
P_{\mathrm{GO} \text { ER }}(N, n)=\left(\begin{array}{c}
N \\
n
\end{array}\right) P_{\mathrm{GO} \text { error }}{ }^{n}\left(1-P_{\mathrm{GO} \text { error }}\right)^{N-n}
$$

where:

- $\mathrm{P}_{\mathrm{GO} \text { error }}$ : probability of geo-object erroneous recognition

$$
\begin{aligned}
& \circ \text { undercharging: } \mathrm{P}_{\mathrm{GO} \text { error }}=\mathrm{P}_{\mathrm{MR}} \\
& \circ \text { overcharging: } \mathrm{P}_{\mathrm{GO} \text { error }}=\mathrm{P}_{\mathrm{FR}}
\end{aligned}
$$

- $\mathrm{N}$ : number of involved geo-segments

○ undercharging: number of geo-objects the user has travelled trough during the invoice period that risk to be missed with a probability of $\mathrm{P}_{\mathrm{MR}}$

o overcharging: number of geo-objects the user has not used during the invoice period but risk to be charged with a probability of $\mathrm{P}_{\mathrm{FR}}$

Considering only over- or under-charging, but not the compensation of both error types in the same invoice, the maximum number of erroneously recognized geo-objects $\left(\mathrm{n}_{\max }\right)$ that meets the maximum allowed invoice error $(\mathrm{x} \%)$ is:

$$
\begin{aligned}
& n_{\max }=0 \text { for } 1 \leq N<\left\lceil\frac{100}{x}\right\rceil \\
& n_{\max }=k \text { for }\left\lceil k \cdot \frac{100}{x}\right\rceil \leq N<\left\lceil(k+1) \cdot \frac{100}{x}\right\rceil
\end{aligned}
$$

Then, the probability of an invoice to meet the application integrity requirements is:

$$
\frac{X}{100}=p\left(n \leq n_{\max }\right)=\sum_{n=0}^{n_{\max }} P_{\mathrm{GO} \mathrm{ER}}(N, n)
$$

If $\mathrm{P}_{\mathrm{GO} \text { error }}<\mathrm{x} / 100$, the worst (smallest) probability $\mathrm{X}$ that the invoice will meet the requirements given a fixed value of $\mathrm{P}_{\mathrm{GO} \text { error }}$ occurs with:

- $n_{\max }=0$

- $\quad N=\lceil 100 / x\rceil-1$
Thus, the geo-object recognition performance that meets the invoice requirements $(\mathrm{x} \%, \mathrm{X} \%)$ in the worst case is:

$P_{\mathrm{GO} \text { error }}(X, x$, worst case $)=1-\left(\frac{X}{100}\right)^{[100 / x-1}$

Worst case values of $\mathrm{P}_{\mathrm{GO}}$ error are collected in TABLE 1 for different invoice requirements. For example, achieving a maximum loss of revenue of $\mathrm{x}=1 \%$ in $\mathrm{X}=99 \%$ of the invoices requires a geo-object missed recognition rate of $\mathrm{P}_{\mathrm{MR}}=1 \mathrm{e}-4$. This is valid when the user has travelled through $\mathrm{N}=99$ segments; other number of geo-objects would relax the $\mathrm{P}_{\mathrm{MR}}$ requirement. Another example, from an overcharging point of view: a user that travels close enough of $\mathrm{N}=999$ road segments that risk to be charged will not be charge a single geo-object the $X=99.9 \%$ of the times if geo-object false recognition rate is $\mathrm{P}_{\mathrm{FR}}=1 \mathrm{e}-6$.

TABLE $1 . \mathrm{P}_{\mathrm{GO} \text { erRor }}$ THAT MEETS INVOICE REQUIREMENTS IN THE WORST CASE

\begin{tabular}{|c|c|c|c|c|}
\hline \multirow{2}{*}{$\begin{array}{c}\text { Worst case } \\
\mathbf{P}_{\text {MR }}, \mathbf{P}_{\text {FR }}\end{array}$} & \multicolumn{3}{|c|}{$\mathbf{N}$} \\
\cline { 3 - 5 } & & $\mathbf{1} \%$ & $\mathbf{0 . 1} \%$ & $\mathbf{0 . 0 1} \%$ \\
\hline \multirow{3}{*}{$\mathbf{X}$} & $\mathbf{9 9 \%}$ & $\mathbf{9 9}$ & $\mathbf{9 9 9}$ & $\mathbf{9 9 9 9}$ \\
\cline { 2 - 5 } & $\mathbf{9 9 . 9 \%}$ & $1 \mathrm{e}-4$ & $1 \mathrm{e}-5$ & $1 \mathrm{e}-6$ \\
\cline { 2 - 5 } & $\mathbf{9 9 . 9 9 \%}$ & $1 \mathrm{e}-6$ & $1 \mathrm{e}-6$ & $1 \mathrm{e}-7$ \\
\hline
\end{tabular}

\section{GNSS integrity requirements}

Geo-object recognition is done with the user's GNSS estimated positions that have satisfactorily passed the RAIM, i.e., HPL $<$ HAL and no position failure detected by the FD. Some of these positions are actually hazardous misleading information (HMI), that is, position failures not detected by the RAIM. $\mathrm{P}_{\text {int }}$ is the GNSS contribution to the probability of HMI.

Geo-object recognition is affected by HMI only when the user's real and estimated positions are in different sides of the road segment. In this paper it is assumed that every HMI affects geo-object recognition, which gives conservative HMI requirements. Both under- and over-charging HMI are assumed to occur with the same probability $\mathrm{p}_{\mathrm{HMI}}$.

Geo-object recognition is triggered when there is at least one estimated position inside it. First, all the GNSS positions related with the geo-object are collected and used afterwards to decide whether the vehicle has circulated through the segment or not. The set of GNSS positions can be collected taking all the positions calculated during the interval of time between the first and last estimated positions inside the toll segment. Nevertheless, some estimated positions out of the segment that should be included in the recognition process may not be selected with this method. Applying the maximum likelihood estimation to geo-object recognition based on the number of independent position estimations that are inside and outside it, a majority voting rule is obtained:

$\mathrm{N}$ positions inside $>\mathrm{N}$ positions outside $\Rightarrow$ user inside

$\mathrm{N}$ positions inside $\leq \mathrm{N}$ positions outside $\Rightarrow$ user outside 
Consequently, the probabilities of geo-object false and missed recognition depend on the number of available independent position estimations $\left(\mathrm{N}_{\text {pos }}\right)$ to perform the geoobject recognition.

$$
\begin{gathered}
p_{\mathrm{FR}}=\sum_{n=\left\lfloor N_{p o s} / 2\right\rfloor+1}^{N_{p o s}}\left(\begin{array}{c}
N_{p o s} \\
n
\end{array}\right) \cdot p_{H M I}{ }^{n} \cdot\left(1-p_{H M I}\right)^{N_{p o s}-n} \\
p_{\mathrm{MR} \mid H M I}=\sum_{n=\left\lceil N_{p o s} / 2\right]}^{N_{p o s}}\left(\begin{array}{c}
N_{p o s} \\
n
\end{array}\right) \cdot p_{H M I}{ }^{n} \cdot\left(1-p_{H M I}\right)^{N_{p o s}-n}
\end{gathered}
$$

Missed recognition also depends on HMI and GNSS availability, the formula (6) gives the contribution due to HMI.

The segment recognition performance strongly depends on the number of independent estimated positions. Two independent samples already improve the false recognition rate with respect the probability of HMI, while an improvement of missed recognition requires at least three. Estimated positions of single-frequency receivers are likely to be correlated along the geo-object because of the long correlation time of the residual ionospheric delay (around 30 minutes), which usually reduces the number of independent position samples per geoobject to one. On the other hand, dual frequency receivers may perform segment recognition with several independent samples because the main error sources are thermal noise and multipath, with correlation time of a few seconds.

Finally, the HMI probability is distributed in a risk tree to the different subsystems that contribute to its generation (Figure 1). An equal division to each branch is proposed. The quantity allocated at GNSS is the integrity risk. It is important to note that there are also integrity requirements for the GNSS receiver and the database used.

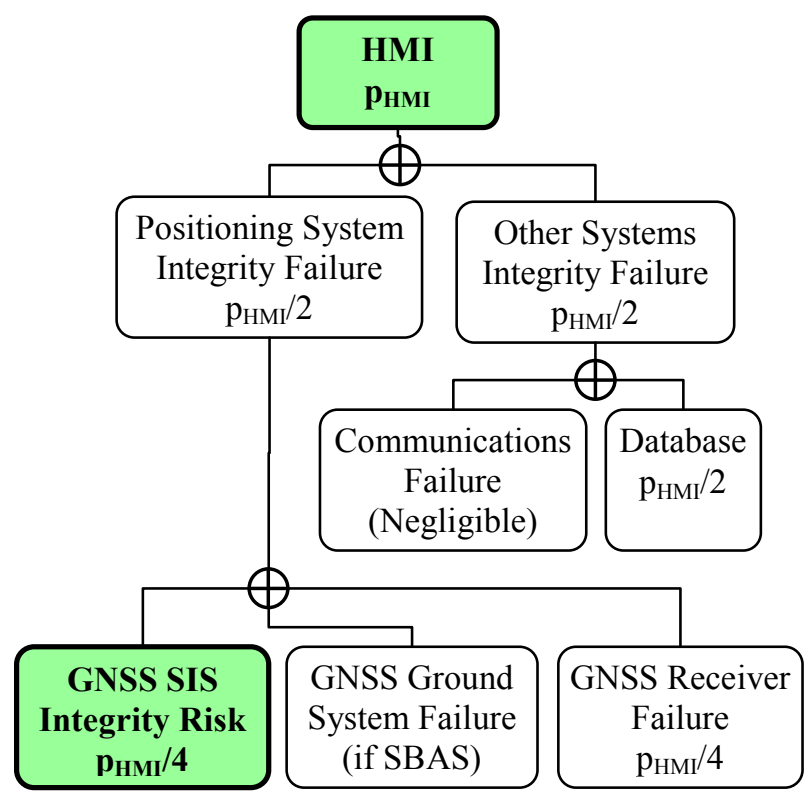

Figure 1. Distribution of HMI risk to obtain the GNSS integrity risk
The $\mathrm{P}_{\mathrm{MA}}$ can be obtained from the Pint and the probability of horizontal position failure:

$$
P_{\text {int }}=P_{\text {horizontal position failure }} \cdot P_{M A}
$$

The probability of position failure depends on the errors in nominal and faulty conditions and on the GNSS integrity requirements $\left(\mathrm{P}_{\text {int }}, \mathrm{HAL}\right)$.

The required $\mathrm{P}_{\mathrm{FA}}$ can be obtained from the $\mathrm{P}_{\mathrm{MR}}$ associated to the undercharging requirement. Geo-object missed recognition can be caused by HMI with the probability of (6) and by GNSS integrity unavailability. In turn, there are three possible sources of unavailability: not enough visible satellites, detected position failures and false alerts. Then, $\mathrm{P}_{\mathrm{FA}}$ can be obtained from knowledge of satellite visibility, probability of position failure and $\mathrm{P}_{\mathrm{MA}}$.

\section{PSEUDORANGE NOMINAL MEASUREMENT MODEL}

The pseudorange nominal measurement model suitable for road tolling in urban environments of [8] has been used. It provides a zero-mean normal distribution that overbounds the expected pseudorange measurement error for road users in urban environments under nominal conditions. The model consists on the error variance as a function of the satellite elevation angle, user's position and $\mathrm{C} / \mathrm{N}_{0}$ for different receiver types:

- GPS, Galileo, standalone or with SBAS corrections

- Current and future signals

- $\quad$ Single- and dual-frequency

Five independent error sources compose the total error: thermal noise and interferences, ionospheric delay, tropospheric delay, inaccuracies in the broadcast ephemeris and satellite corrections, and multipath. The total error variance is:

$$
\sigma_{P S R}^{2}=\sigma_{\text {noise }}^{2}+\sigma_{\text {iono }}^{2}+\sigma_{\text {tropo }}^{2}+\sigma_{\text {clock \& ephem }}^{2}+\sigma_{\text {multipath }}^{2}
$$

Known and validated models have been used for the SV clock and ephemeris pseudorange equivalent errors, thermal noise, tropospheric delay and GPS ionospheric delay. The residual ionospheric delay for Galileo has been calculated using a ionospheric VTEC database, and simulations were carried out to obtain nominal values of SBAS corrections. The multipath error has been computed with a GNSS multipath generator for road users in urban environments [9] and a receiver simulator. Because most of the NLOS multipath with a large bias had a strong phase change that caused tracking loss, the multipath error model does not include large NLOS bias. The receiver is assumed to be able to reject most of them (with $\mathrm{C} / \mathrm{N}_{0}$ check, for instance); if large NLOS bias need to be included, they have to be added to this nominal mode.

\section{THREAT MODEL}

The threat model characterizes the pseudorange errors not considered in the nominal measurement model. This section analyses the threat model keeping in mind it is derived only from GNSS major service failures. 


\section{A. GPS major service failure}

A GPS SPS SIS major service failure is defined to occur whenever the instantaneous URE of a healthy satellite exceeds 4.42 times the bound of the transmitted URA without a timely alert being issued [10]. The probability of major service failure in any healthy satellite in the whole constellation is:

$$
p_{\text {sat MSF }}=10^{-5} / h
$$

In order to analyze the Galileo's threat model, the same major service failure definition and properties as for GPS will be taken.

The probability of a number $\mathrm{k}$ of simultaneous major service failures for a receiver tracking $\mathrm{N}$ satellites is:

$$
p_{\text {rex MSF }}(N, k)=\left(\begin{array}{c}
N \\
k
\end{array}\right) \cdot p_{\text {sat MSF }}^{k} \cdot\left(1-p_{\text {sat MSF }}\right)^{N-k}
$$

Only single failures will be considered in the critical bias computation.

\section{B. Critical bias}

The critical bias is defined as the minimum bias at a given satellite's pseudorange that would cause a position integrity failure; in other words, it is the minimum bias the RAIM should detect with the required $\mathrm{P}_{\mathrm{MA}}$. Its magnitude should be large enough to be consistent with the assumption of major service failure (URE larger than 4.42 times the URA). Since in previous versions of [8] major services failures have an URE larger than 30 meters, and assuming current performance is not worse, that magnitude is taken to check if the critical biases can be considered caused by major service failures. If the critical bias is lower than 30 meters, the threat model includes other error sources apart from major service failure and the bias cannot be assured to occur with probability $\mathrm{p}_{\text {sat MSF }}$.

The horizontal position error in the fault free scenario, caused only by nominal errors, follows a bivariate normal distribution centered at the true position in the horizontal local plane. The contours of equal probability density are ellipses with the axes in the directions of the eigenvectors of the horizontal error covariance matrix $\left(\mathrm{C}_{\mathrm{H}}\right)$ and variance equal to their corresponding eigenvalues.

$$
\varepsilon_{H, \text { fault free }} \sim \mathrm{N}\left(0, \mathrm{C}_{\mathrm{H}}\right)
$$

Let us model satellite failures as pseudorange biases. Then, the horizontal position error follows the same bivariate normal distribution as in the fault free scenario (because nominal errors remain the same), centered at bias projection on the horizontal local plane $\left(b_{H}\right)$.

$$
\varepsilon_{H, b_{H}} \sim \mathrm{N}\left(\mathrm{b}_{\mathrm{H}}, \mathrm{C}_{\mathrm{H}}\right)
$$

The probability of a horizontal position integrity failure is:

$$
\begin{aligned}
P\left(\varepsilon_{H}>H A L\right)=(1 & \left.-p_{r c x M S F}\right) \cdot P\left(\varepsilon_{H}>H A L \mid \text { fault free }\right)+ \\
& +p_{r c x M S F} \cdot P\left(\varepsilon_{H}>H A L \mid \text { faulty case }\right)
\end{aligned}
$$

The critical bias is obtained setting the probability of integrity failure equal to the integrity risk in of eq.(13):

$$
\begin{aligned}
P_{\text {int }}=(1 & \left.-p_{r c x M S F}\right) \cdot P\left(\varepsilon_{H}>H A L \mid \text { fault free }\right)+ \\
& +p_{r c x M S F} \cdot P\left(\varepsilon_{H}>H A L \mid \text { critical bias }\right)
\end{aligned}
$$

The critical bias depends on the integrity requirements $\left(\mathrm{P}_{\text {int }}\right.$ and HAL), the nominal measurement model, the method used to estimate the user position, which is a function of the overall geometry between the user and the tracked satellites, and the position of the faulty satellite. Critical biases are independent from the RAIM algorithm.

Critical biases have been computed in different environments following the method explained in [11] with the nominal 24-satellite GPS and 27-satellite Galileo constellations over a $2^{\circ}$-step user position grid covering Europe (longitude: $\left[9^{\circ} \mathrm{W}-43^{\circ} \mathrm{E}\right]$, latitude: $\left.\left[32^{\circ} \mathrm{N}, 72^{\circ} \mathrm{N}\right]\right)$. The user's position is considered to be estimated with a weighted least squares algorithm with weights equal to the inverse of the variance of the nominal error. Data has been computed every 4 minutes during a 72-hour period in order to complete an approximate Earth track of Galileo's satellites. The integrity risk has been set to $1 \mathrm{e}-4 / \mathrm{h}$ and the HAL to 50 meters.

Three scenarios have been considered: open air and two different urban environments (TABLE 2). The minimum mask angle for GPS is $5^{\circ}$ and $10^{\circ}$ for Galileo [6][12]. As in the calculation of the nominal multipath error model used in Section V, the urban scenarios have been simulated in a similar way as in [13]: a constant width street with buildings at both sides, which height and length are normally distributed. Gaps are statistically included to simulate street crossings. Only signals with LOS are considered visible.

Two different receiver types have been studied (TABLE 3) in the following three single- and dual- constellation (GPS/Galileo) configurations:

1) Dual frequency L1/L5, E1/E5a

2) L1/E1 with SBAS ionospheric corrections

3) L1/E1 without SBAS corrections

TABLE 2. CHARACTERISTICS OF SIMULATED URBAN ENVIRONMENTS

\begin{tabular}{|c|c|c|c|c|c|}
\hline No. & street & user distance to & gap & \multicolumn{2}{|c|}{ gap length } \\
\cline { 5 - 6 } scenario & width & left building & prob. & pdf & [min, max] \\
\hline scenario 1 & $20 \mathrm{~m}$ & $10 \mathrm{~m}$ & 0.1 & $\mathrm{~N}(15 \mathrm{~m}, 25 \mathrm{~m})$ & {$[10 \mathrm{~m}, 50 \mathrm{~m}]$} \\
\hline scenario 2 & $20 \mathrm{~m}$ & $10 \mathrm{~m}$ & 0.1 & $\mathrm{~N}(15 \mathrm{~m}, 25 \mathrm{~m})$ & {$[10 \mathrm{~m}, 50 \mathrm{~m}]$} \\
\hline
\end{tabular}

\begin{tabular}{|c|c|c|c|c|}
\hline \multirow{2}{*}{$\begin{array}{c}\text { No. } \\
\text { scenario }\end{array}$} & \multicolumn{2}{|c|}{ building length } & \multicolumn{2}{c|}{ building height } \\
\cline { 2 - 5 } & pdf & {$[\mathbf{m i n}, \mathbf{m a x}]$} & pdf & {$[\mathbf{m i n}, \mathbf{m a x}]$} \\
\hline scenario 1 & $\mathrm{~N}(20 \mathrm{~m}, 25 \mathrm{~m})$ & {$[10 \mathrm{~m}, 50 \mathrm{~m}]$} & $\mathrm{N}(15 \mathrm{~m}, 7 \mathrm{~m})$ & {$[4 \mathrm{~m}, 50 \mathrm{~m}]$} \\
\hline scenario 2 & $\mathrm{~N}(15 \mathrm{~m}, 25 \mathrm{~m})$ & {$[10 \mathrm{~m}, 50 \mathrm{~m}]$} & $\mathrm{N}(6 \mathrm{~m}, 3 \mathrm{~m})$ & {$[4 \mathrm{~m}, 20 \mathrm{~m}]$} \\
\hline
\end{tabular}

TABLE 3. RECEIVER TYPES
\begin{tabular}{|c|c|c|c|c|}
\hline Rcx type & f & $\begin{array}{c}\text { Receiver } \\
\text { modulation }\end{array}$ & $\begin{array}{c}\text { Front End } \\
\text { bandwidth }\end{array}$ & E-L spacing \\
\hline Rcx L1/E1 & L1/E1 & BOC $(1,1)$ & $4 \mathrm{MHz}$ & 0.2 chips \\
\hline Rcx L5/E5a & L5/E5a & BPSK $(10)$ & $20 \mathrm{MHz}$ & 0.25 chips \\
\hline
\end{tabular}


The difference between GPS and Galileo time is supposed to be known, so the minimum number of tracked satellites required in RAIM for bi-constellation receivers is five.

Receiver configuration 2 assumes SBAS ionospheric corrections for Galileo with the same residual error as for GPS.

The $\mathrm{C} / \mathrm{N}_{0}$ is set to $36 \mathrm{dBHz}$ for $\mathrm{L} 1 / \mathrm{E} 1$ and $30 \mathrm{dBHz}$ for L5/E5a signals. The standard deviation of the equivalent range error of SV clock and ephemeris inaccuracies is set to $0.85 \mathrm{~m}$., the maximum SISA required in Galileo.

\section{1) Scenario 0. Open air}

The scenario has no obstacles and all satellites above the minimum mask angle are considered visible. For single constellation GPS and Galileo the number of visible satellites is equal or higher than 5 at all epochs.

Dual frequency receivers (configuration 1) provide the critical error distribution of Figure 2. Two types of statistics are plotted: the critical bias of all visible satellites and the critical bias of the worst satellite, that is, the minimum critical bias among those of all visible satellites at a given epoch. The minimum critical bias at any epoch is 87 meters for GPS/Galileo, $51 \mathrm{~m}$. for Galileo and $25 \mathrm{~m}$. for GPS. The probability of having a critical bias lower than $30 \mathrm{~m}$. with GPS is $1.6 \mathrm{e}-5$, so the assumption of bias caused by major service failures is consistent.

Single frequency receivers with SBAS ionospheric corrections (configuration 2) have similar nominal errors as dual frequency ones, and consequently similar critical bias.

Nominal errors in single frequency receivers without SBAS (configuration 3) are considerably much larger than in the previous configurations, which consequently increases the probability of horizontal position failures in fault-free conditions. At some epochs, the integrity risk is reached in fault free conditions, leaving no probability margin to be allocated to the faulty case:

$$
P_{\text {int }}<\left(1-p_{\text {rcx MSF }}\right) \cdot P\left(\varepsilon_{H}>H A L \mid \text { fault free }\right)
$$

When this happens the critical bias is zero, as nominal errors already put the system out from the integrity requirements and RAIM cannot be used. This fact occurs with very low probability in single constellation receivers: the probability of having a critical bias lower than $30 \mathrm{~m}$. is $2.9 \mathrm{e}-3$ for GPS and 4e-5 for Galileo. Bi-constellation GPS/Galileo never reach the $\mathrm{P}_{\text {int }}$ in fault free conditions and have a minimum critical bias of $69 \mathrm{~m}$. Thus, the major service failure assumption is consistent for bi-constellation receivers, and an approximation for single constellation ones.

The number of visible satellites and their geometry have a very important effect on the position error. For instance, the probability of low critical biases increases as the number of visible satellites decreases in Figure 4.

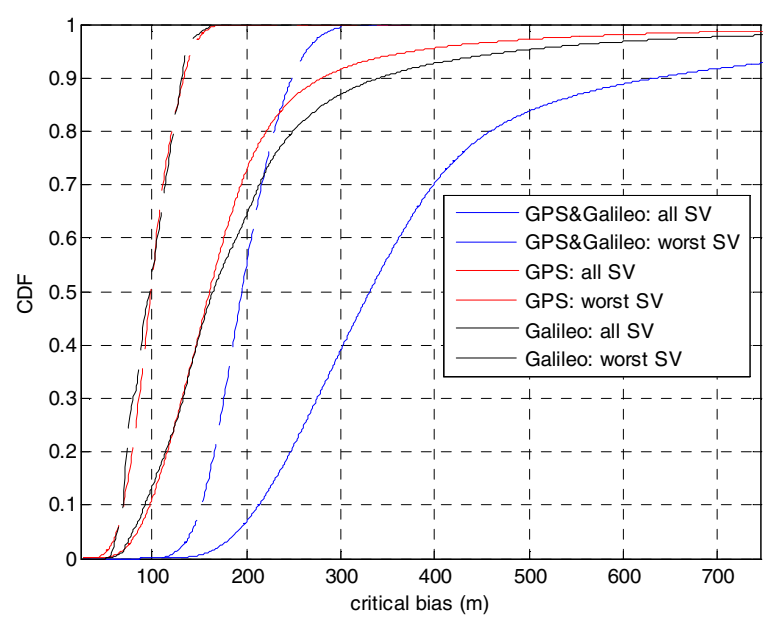

Figure 2. Critical bias CDF for receiver configuration 1 in the scenario 0

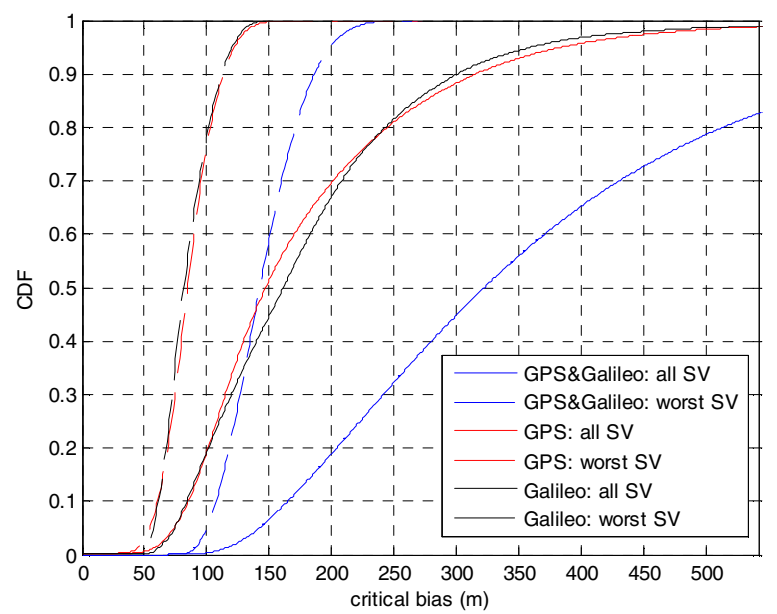

Figure 3. Critical bias CDF for receiver configuration 3 in the scenario 0

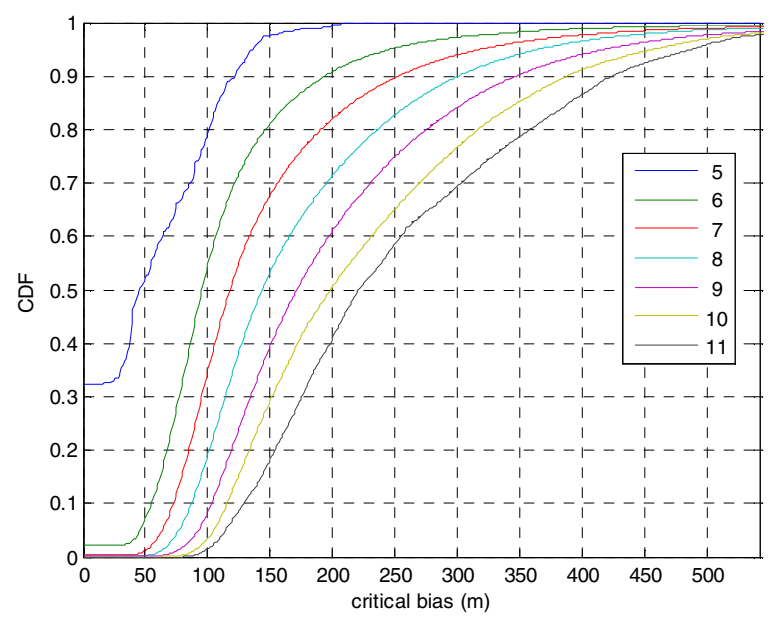

Figure 4. Critical bias CDF for standalone GPS (conf.iguration 3) in function of the number of visible satellites in scenario 0 . 
2) Scenario 1. Urban environment (type 1)

The scenario represents a wide street with reasonably high buildings as the ones that can be found in the center of certain cities. The average mask angle caused by buildings is a function of the satellite azimuth with respect to the street axis, with a maximum of $56.3^{\circ}$ for satellites received at the perpendicular direction to the street axis. This fact will affect to the distribution of visible satellites and hence the error distribution and the critical bias.

TABLE 4 contains the percentage of epochs with five or more visible satellites, as well as the percentage of epochs with a critical bias larger than zero (i.e., five or more satellites and probability of position failure in fault free conditions lower than the integrity risk). Visibility results for the same constellations are slightly different from a configuration to another because they correspond to different simulation runs.

Configurations 1 and 2 provide similar results (Figure 5). Single constellations provide poor visibility results and low critical bias with high. Bi-constellation receivers provide important advantages in terms of satellite visibility, but there are still some epochs with critical bias zero. Nevertheless, the probability of a critical bias lower than $30 \mathrm{~m}$. is 0.08 .

Non-SBAS single frequency receivers have a high percentage of low critical biases, so the assumption of major failure fails (Figure 6).

\section{3) Scenario 0. Urban environment (type 2)}

The scenario represents a street with relatively small buildings as the ones that can be found in suburban areas.

Bi-constellation receivers reach the required number of visible satellites almost $100 \%$ of the cases, while this value is reduced to $95 \%$ for Galileo and to $80 \%$ for GPS (TABLE 5).

Configurations 1 and 2 have critical biases lower than 30 meters, including of magnitude zero, so they cannot be said to be strictly caused by major service failures. Nevertheless, the probability of a critical bias lower than 30 meters is $3 \mathrm{e}-4$ for GPS/Galileo, 5.5e-3 for Galileo and 0.02 for GPS (Figure 7).

Single constellation receivers with configuration 3 have too low magnitude critical biases to be considered major service failures, but the probability of a critical bias lower than 30 meters is $9 \mathrm{e}-3$ for bi-constellation receivers (Figure 8).

TABLE 4. STATISTICS OF SATELITE VISIBILITY AND CRITICAL BIAS ZERO (SCENARIO 1)

\begin{tabular}{|c|c|c|c|}
\hline Configuration 1 & GPS/Galileo & GPS & Galileo \\
\hline Epochs with no. visible sat. $\geq 5(\%)$ & 93.06 & 16.60 & 33.39 \\
\hline Epochs with critical bias $>0(\%)$ & 89.91 & 16.24 & 30.77 \\
\hline Configuration 2 & GPS/Galileo & GPS & Galileo \\
\hline Epochs with no. visible sat. $\geq 5(\%)$ & 91.26 & 17.78 & 34.97 \\
\hline Epochs with critical bias $>0(\%)$ & 89.02 & 17.46 & 32.91 \\
\hline
\end{tabular}

\begin{tabular}{|c|c|c|c|}
\hline Configuration 3 & GPS/Galileo & GPS & Galileo \\
\hline Epochs with no. visible sat. $\geq \mathbf{5}(\%)$ & 92.38 & 17.82 & 34.25 \\
\hline Epochs with critical bias $>\mathbf{0}(\%)$ & 51.87 & 10.50 & 12.10 \\
\hline
\end{tabular}

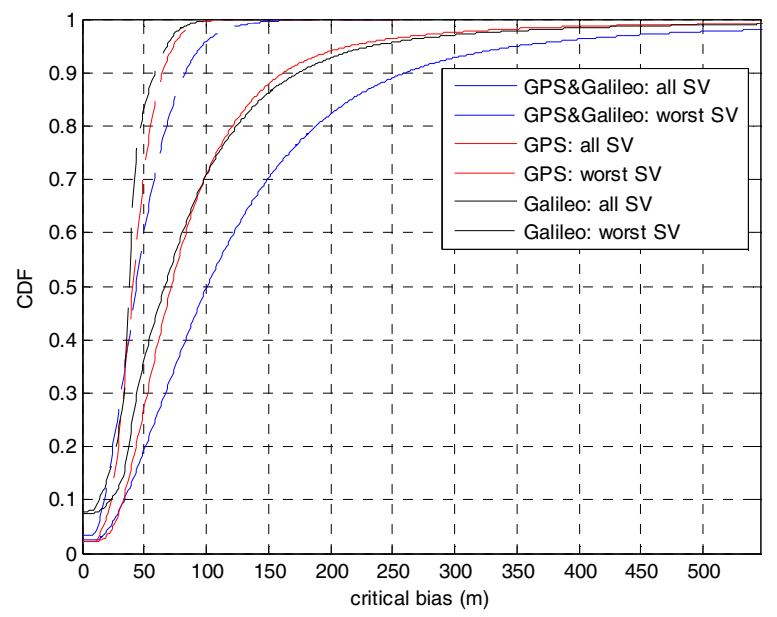

Figure 5. Critical bias CDF for receiver configuration 1 in the scenario 1

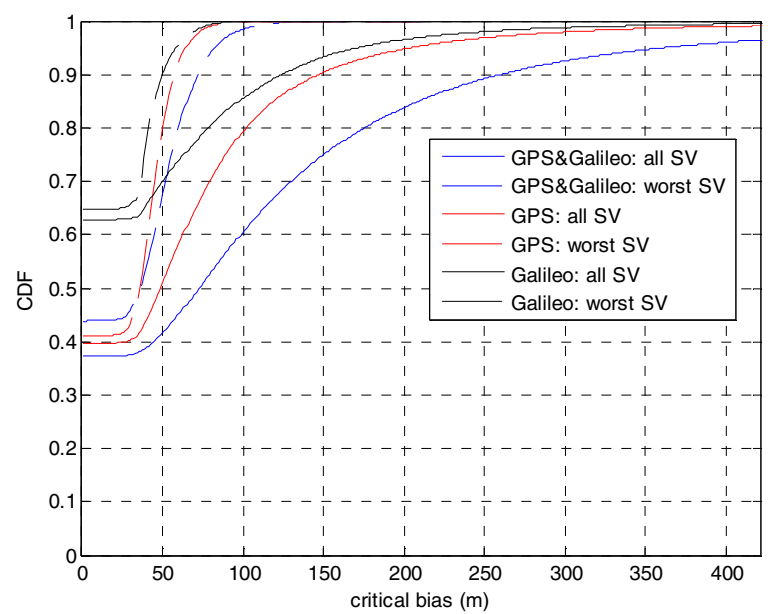

Figure 6. Critical bias CDF for receiver configuration 3 in the scenario 1

TABLE 5. STATISTICS OF SATELITE VISIBILITY AND CRITICAL BIAS ZERO (SCENARIO 2)

\begin{tabular}{|c|c|c|c|}
\hline Configuration 1 & GPS/Galileo & GPS & Galileo \\
\hline Epochs with no. visible sat. $\geq \mathbf{5}(\boldsymbol{\%})$ & 99.99 & 80.84 & 95.11 \\
\hline Epochs with critical bias $>\mathbf{0}(\boldsymbol{\%})$ & 99.99 & 80.44 & 94.82 \\
\hline
\end{tabular}

\begin{tabular}{|c|c|c|c|}
\hline Configuration 1 & GPS/Galileo & GPS & Galileo \\
\hline Epochs with no. visible sat. $\geq \mathbf{5}(\%)$ & 99.98 & 80.69 & 94.83 \\
\hline Epochs with critical bias $>\mathbf{0}(\mathbf{\%})$ & 99.97 & 80.37 & 94.63 \\
\hline
\end{tabular}

\begin{tabular}{|c|c|c|c|}
\hline Configuration 1 & GPS/Galileo & GPS & Galileo \\
\hline Epochs with no. visible sat. $\geq \mathbf{5}(\%)$ & 99.99 & 81.48 & 95.19 \\
\hline Epochs with critical bias $>\mathbf{0}(\%)$ & 98.68 & 66.50 & 70.08 \\
\hline
\end{tabular}




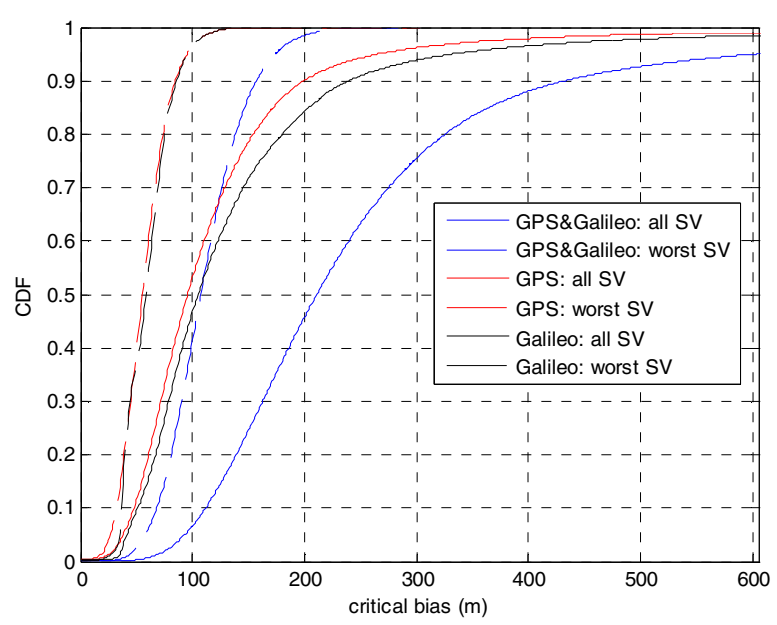

Figure 7. Critical bias CDF for receiver configuration 1 in the scenario 3

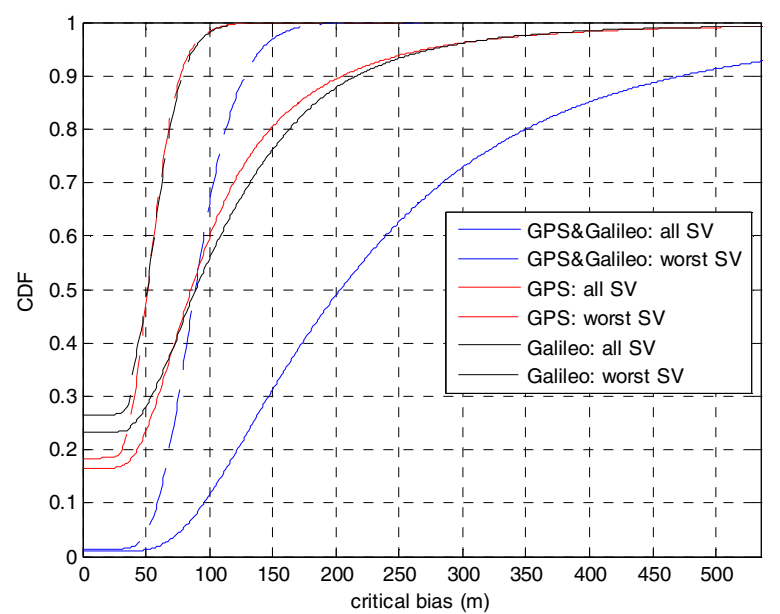

Figure 8. Critical bias CDF for receiver configuration 3 in the scenario 3

To conclude, for the given GNSS integrity requirements, the assumption of critical biases caused only by major service failures holds for open air scenarios, but not always in urban environments with reduced visibility. In general, biconstellation receivers increase the satellite visibility in urban environments, providing consequently better satellite geometries. Thus, critical biases in bi-constellation dualfrequency or SBAS receivers, although do not always meet the assumption of major service failures, provide low probability of having a critical bias below 30 meters. On the other hand, this cannot be always said for single constellation or single frequency non-SBAS receivers, which would need less stringent integrity requirements.

\section{CONCLUSIONS}

The paper has presented the required parameters in the design of RAIM algorithms for road tolling applications in urban environments.
First, integrity monitoring concepts and the parameters needed in the design of RAIM algorithms have been presented. These parameters are the GNSS integrity requirements (integrity risk and HAL), the RAIM performance (missed and false alarm rate) and the error characterization in nominal and faulty conditions. Afterwards, the integrity risk has been derived from the application needs. The effect of the correlation time of position errors has been highlighted, reasoning that single frequency receivers are likely to have poorer segment recognition performance due to the large correlation time of the ionospheric delay. The position errors have been characterized in the nominal and faulty conditions. A pseudorange nominal measurement model suitable for road users in urban environments has been used. Finally, the threat model for satellite major failures has been computed for different receiver configurations and scenarios. The critical bias has been analyzed, showing the higher performance, compared to other receiver configurations, of bi-constellation receivers with dual frequency or SBAS ionospheric corrections in urban environments.

\section{REFERENCES}

[1] European Parliament and the Council of the European Union, "on the interoperability of electronic road toll systems in the Community", Official Journal of the European Union, 29 April 2004

[2] Toll Collect, "Truck toll in Germany. User information", Edition 2009

[3] NDSAS (Motorways and Express roads in Slovakia), "Multi-lane freeflow electronic tolling in the Slovak Republic", February 2010

[4] "Explanatory memorandum of the Dutch road pricing act", English version, available in the website of the Dutch Ministry of Transport, Public Works and Water Management

[5] Ministry of Ecology, Energy, Sustainable development and Regional development of France, "Partnership contract concerning the national HGV eco-tax and the Alsace experimental tax. Project presentation note", March 31, 2009 (English version November 2, 2009)

[6] Radio Technical Commission for Aeronautics (RTCA), "Minimum Operational Performance Standards (MOPS) for Global Positioning System (GPS)/ Wide Area Augmentation System (WAAS) Airborne Equipment", RTCA DO-229D, December 2006

[7] B.W. Parkinson, P. Axelrad, "Autonomous GPS integrity monitoring using the pseudorange residual", Navigation: Journal of the Institite of Navigation, Vol. 35, No. 2, Summer 1988

[8] D. Salós, C. Macabiau, A. Martineau, B. Bonhoure, D. Kubrak, "Nominal GNSS pseudorange measurement model for vehicular urban applications", IEEE/ION PLANS, 3-6 May 2010

[9] A. Lehner, A. Steingass, "A novel channel model for land mobile satellite naviagtion", ION GNSS 18th International Technical Meeting of the Satellite Division, 13-16 Sept. 2005

[10] DoD, "Global Positioning System Standard Positioning Service Performance Standard", 4th Edition, September 2008

[11] A. Martineau, "Performance of receiver autonomous integrity monitoring (RAIM) for vertically guided approaches", $\mathrm{PhD}$ thesis, Institute National Polytechnique de Toulouse, 2008

[12] EUROCAE, "Interim minimum performance specification for airborne Galileo satellite receiving equipment", version 0.25, October 2007

[13] B. Krach, A. Steingass, A. Lehner, "Technical note on the implementation of the land mobile satellite channel model - Software usage ", Doc.No: DLR-KN-FS-02-07, Issue No: 2, July 2007 